\title{
Giant Left Atrial Myxoma Presenting with Cough-Syncope Syndrome
}

\author{
Esra Erturk Tekin, MD \\ Mersin City Training and Research Hospital, Cardiovascular Surgery Department, Mersin, Turkey
}

\section{ABSTRACT}

We report the case of a 41-year-old female patient with symptoms of cerebrovascular accident manifesting with loss of consciousness during episodes of cough. Computed multislice chest tomography showed a $7.3-$ by $4.15-\mathrm{cm}$ mass in the left atrium. A transesophageal echocardiogram showed a giant mass in the left atrium that passed through the mitral valve to the left ventricle, and severe obstructive stenosis was suggested by the mean transmitral gradient. After a comprehensive assessment of the mass, we decided to perform surgery. The pedunculated and fragile mass was attached to the interatrial septum with its handle, and the majority of it prolapsed through the mitral valve to the left ventricle and became stacked among the mitral valve leaflets. The removed mass was analyzed histopathologically and was found to be a myxoma. It is important for the cardiac surgeon to surgically remove an atrial myxoma because of the risks associated with embolization, including sudden death, as myxoma can block the blood supply from the atrium to the ventricle.

\section{INTRODUCTION}

Myxoma is the most common primary cardiac tumor in adults. Familial factors are considered to play an active role (Ying 2016). Chromosomes 2p, 12, and 17p were reported to have regions associated with myxoma, especially in studies on patients with Carney complex, and it was observed that genetic anomalies played a role (Gur 2012). Histopathologically, these tumors originate from multipotent mesenchymal cells of subendocardial connective tissue consisting of fibroblast cells in a background of gelatinous mucoid tissue.

The classic triad of symptoms-obstructive, embolic, and constitutional-is the common manifestation of a cardiac myxoma (Poterucha 2019). The differential manifestations of left and right atrial myxomas in terms of systemic and pulmonary embolic predilections have drawn attention (Yuan 2014a). A cerebrovascular complication such as a neurological

Received May 22, 2021; fuen 29,2021.

Correspondence: Esra Erturk Tekin, Department of Cardiovascular Surgery, Korukent mah. 96015 sok. Mersin Entegre Sağllk Kampiisii, 33240, Toroslar/ Mersin, Turkey; 90538 2174487; fax: 90 (324) 2251010 (e-mail:dresraer@ yahoo.com). deficit or sensory impairment as an onset symptom may prompt a suspicion of a cardiac myxoma much earlier (Yuan 2014b). Complaints of patients are related to tumor size. If the tumoral structure is small, the patient may be asymptomatic. Cardiac complaints such as dyspnea, orthopnea, pulmonary edema, hemoptysis, coughing, and fainting may be observed as the tumoral structure becomes larger. Peripheral embolism-related ischemia and cranial embolism-related plegia may be observed (Abu Abeeleh 2017). In addition, the miscellaneous and uncharacteristic clinical manifestations of a cardiac myxoma vary considerably on a case-to-case basis. This peculiarity of the presenting symptoms often leads to delayed presentation and a delayed diagnosis, eventually resulting in unexpected poor prognosis.

As the number of patients with cardiac myxoma is increasing, transthoracic echocardiography (TTE) and transesophageal echocardiography (TEE) are widely used in routine cardiology practice to diagnose and monitor the disease. A diagnostic approach to patients with cardiac myxoma is based on medical history, clinical examination, blood test results, and radiographic or echocardiographic findings. Computed tomography (CT) of the chest and magnetic resonance imaging (MRI) of the chest or the heart help with the differential diagnosis, which includes cardiac tumors and masses. Therefore, a comprehensive understanding of the usual aspects of cardiac myxomas is extremely important for an early diagnosis and prompt treatment.

It is rare to observe a myxoma among the mitral leaflets. Mitral valve obstruction causes a sudden increase in left atrial pressure, causing the patient to cough. In addition, syncopal episodes may occur because of the large left atrial mass obstructing the outflow of blood to the brain. Thus, the mass should be removed surgically as soon as possible after diagnosis.

\section{CASE REPORT}

A 41-year-old female patient presented to the emergency department with several-months-long exertional dyspnea after walking only a few steps, with subsequent nonproductive coughing episodes leading to syncopal events. These episodes had happened over the past 6 months and had worsened over the month before presentation. The patient was unable to work for fear of coughing and suddenly losing consciousness. The patient also had 1-month-long bilateral lower extremity edema and generalized fatigue. Blood pressure range was 110 to $130 \mathrm{mmHg}$ systolic and 80 to $90 \mathrm{mmHg}$ diastolic, heart rate was 90 beats $/ \mathrm{min}$, and body temperature was $37.8^{\circ} \mathrm{C}$. On 

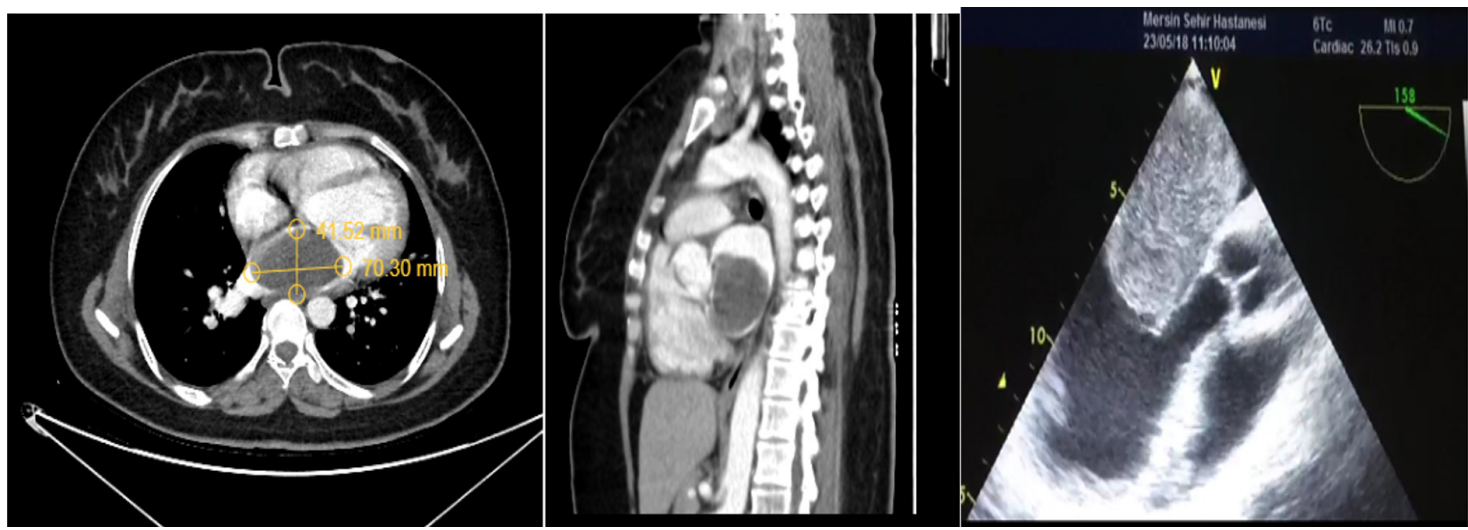

Figure 1. Sagittal, axial CT image and TEE image showing myxoma.

physical examination, significant findings were high jugular vein pressure, loud S1, early diastolic tumor plop, and 2+ pedal edema in bilateral lower extremities. She had an oxygen saturation of $99 \%$ in room air. Lungs were normal to auscultation. Pertinent laboratory work included a brain natriuretic peptide level of $351 \mathrm{pg} / \mathrm{mL}$ and an ESR of $38 \mathrm{~mm} / \mathrm{h}$.

In the emergency department, the patient underwent a CT of the chest, which demonstrated a 7.3- by $4.15-\mathrm{cm}$ mass in the left atrium (Figure 1). On the transesophageal echocardiogram, the left ventricle ejection fraction was $55 \%$ to $60 \%$, and the right ventricle was moderately dilated, with moderate systolic dysfunction. The left atrium was moderately enlarged and was entirely occupied by a massive echodensity (Figure 1).

Severe obstructive stenosis across the mitral valve was suggested by the mean transmitral gradient (Videos 1 and 2). The tricuspid valve showed moderate regurgitation, with a jet velocity suggestive of pulmonary hypertension. Cardiac catheterization performed before surgery showed normal coronary arteries.

The patient underwent cardiac surgery for removal of the left atrial mass, which was subsequently determined to be a left atrial myxoma. The patient agreed to undergo surgical resection of the myxoma via left atriotomy under cardiopulmonary bypass. A majority of the mass had prolapsed through the mitral valve into the left ventricle, so the mass disintegrated during resection. Pathological examination of the bulk showed it was a myxoma by morphology, involving calcification centers (Figure 2). After intensive care and clinical follow-up, the patient was discharged from the hospital. Echocardiography 2 months after the operation showed healing. No bulk recurrence was seen, and the postoperative echocardiographic findings showed complete removal of the mass and trivial mitral and tricuspid regurgitation. Left ventricular ejection fraction was $55 \%$, and systolic pulmonary arterial pressure was $30 \mathrm{mmHg}$. The complaints of respiratory disorders regressed, and no syncope was seen.

\section{DISCUSSION}

Atrial myxomas are the most common primary heart tumors, accounting for $40 \%$ to $50 \%$ of primary cardiac
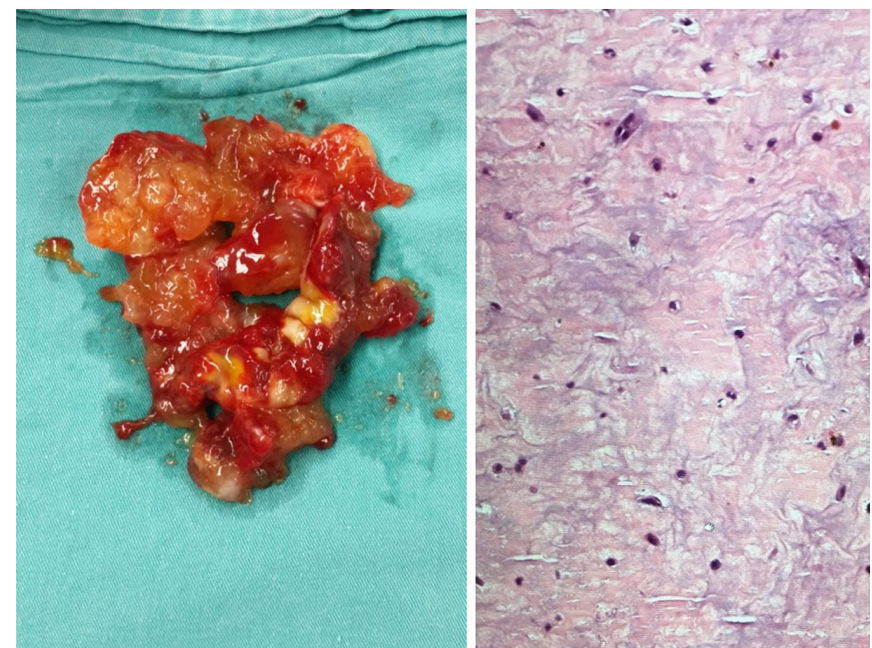

Figure 2. Major part of the mass was prolapsed through the mitral valve to the left ventricle and disintegrated during resection. The bulk histopathological examination was reported as myxoma morphology involving calcification centers.

tumors (Yamada 1993; Amoah 1988). The lifetime risk of developing atrial myxoma is $\sim 0.02 \%$ (Rathore 2008). Primarily, these lesions are benignly localized and identified within the left atrium. Clinically, patients may experience fatigue, dyspnea, angina pectoris, and congestive heart failure from obstructed mitral or tricuspid valvular blood flow. Studies have also indicated that in $~ 15 \%$ of atrial myxoma cases, mechanical valvular heart failure may develop (Levy 2002; Ojji 2008). Left atrial tumors may also obstruct blood flow to the systemic circulation, causing mitral valve regurgitation and heart failure signs and symptoms, and can lead to secondary pulmonary hypertension (Salcedo 1992; Kimberly 2016). Myxomas may also lead to invasion of the myocardium or the adjacent lung, leading to arrhythmias, pericardial effusion, or pulmonary symptoms (Sheu 2007).

TTE usually identifies the mass, but TEE often provides better visualization of the left atrium and allows for clear 


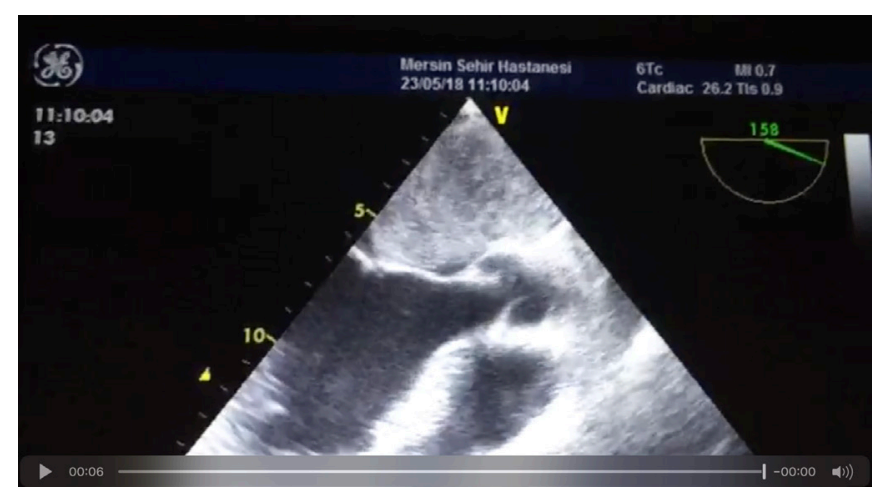

Video 1. https://vimeo.com/588941347

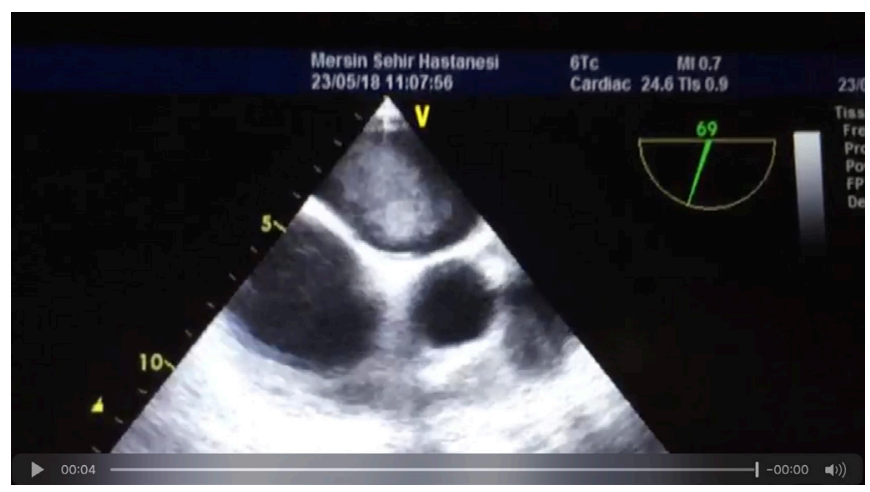

Video 2. https://vimeo.com/588941824 differentiation of a tumor versus a thrombus by determining whether the mass has a stalk (and therefore is a tumor) or is unconnected from the intramyocardial wall (and therefore is a thrombus) (Agmon 1999; Wintersperger 2000). An echocardiogram also provides information about the mass, including whether it obstructs circulation.

Surgical removal is the best treatment option if possible, as the risk of embolization is significant if the atrial myxoma is left in place. The most concerning consequence of an atrial myxoma is the risk of embolization and sudden death, which occurs in up to one-third of patients; therefore, urgent surgical resection of myxomas is recommended (Keeling 2002; Suraj 2009). Postoperative mortality is generally low, $<5 \%$, and the 20 -year survival rate is $\sim 85 \%$ (Suraj 2009). Risk of recurrence is $~ 5 \%$ (Suraj 2009).

In this case report, there was a unique presentation of a left atrial myxoma, although other cases of atrial myxomas discovered after syncopal episodes have also been reported in the literature (Rashidi 2014; Rajani 2015; Strecker 2012). The patient in this case report reported generalized fatigue and symptoms of mitral valve obstruction, including dyspnea on exertion, and loud S1 and a tumor plop (an early diastolic sound due to movement of the myxoma across the mitral valve into the left ventricle) were found on examination. The patient's frequent syncopal episodes can be explained by the large left atrial mass obstructing the outflow of blood to the brain. In addition, mitral valve obstruction caused a sudden increase in left atrial pressure, causing the patient to cough (Bowman 2017).

\section{CONCLUSION}

The diagnosis of atrial myxoma must be considered when a patient is found to have cardiac mass and variable constitutional symptoms that can arise from outflow obstruction or embolization. Surgical removal is the best option to avoid embolization and even sudden death. The prognosis after surgery and in the long term is good.

\section{REFERENCES}

Abu Abeeleh M, Saleh S, Alhaddad E, et al. Cardiac myxoma: clinical characteristics, surgical intervention, intra-operative challenges and outcome. Perfusion 2017;32:686-690.

Agmon Y, Khandheria BK, Gentile F, Seward JB. Echocardiographic assessment of the left atrial appendage. J Am Coll Cardiol 1999;34:1867-1877.

Amoah AGB, Frimpong-Boateng K, Kallen C, Barwasser HM. Atrial myxoma-a case report and review of the literature. West Afr J Med $1988 ; 17: 50-54$.

Bowman JN, Treece JM, Bhattad PB, Bochis M, Bajaj K. Giant left atrial myxoma masquerading as cough-syncope syndrome. J Invest Med High Impact Case Rep 2017;11:1-5.

Gur AK, Kaya Y, Karakurt A, Güvenç TS. Miksoma ve fibroelastomanın e lik etti i Carney sendromlu hasta. Dicle Med J 2012;39:413-415 [in Turkish].

Keeling IM, Overwalder P, Anelli-Monti M, et al. Cardiac myxomas: 24 years of experience in 49 patients. Eur J Cardiothorac Surg 2002;22:971-977.

Kimberly H, Stone M. Elderly man with acute respiratory distress. Ann Emerg Med 2016;67:319-331.

Levy S. Atrial fibrillation, the arrhythmia of the elderly, causes and associated conditions. Anadolu Kardiyol Derg 2002;2:55-60.

Ojji DB, Ajiduku SS, Omonua OO, Abdulkareem LL, Parsonage W. A probable right atrial myxoma prolapsing through the tricuspid valve into the right ventricle: a case report. Cases J 2008;1:386.

Poterucha TJ, Jonathan Kochav J, O'Connor DS, Rosner GF. Cardiac tumors: clinical presentation, diagnosis, and management. Curr Treat Options Oncol 2019;20:66.

Rajani AR, Muaz RN, Govindaswamy PR, Mian MH. Arryhmias are not to blame for all cardiac syncope patients: left atrial myxoma causing syncope in a middleaged man. BMJ Case Rep 2015; 2015:bcr2014209119.

Rashidi N, Montazeri M, Montazeri M. Large left atrial myxoma causing mitral valve obstruction: a rare cause of syncope. J Cardiovasc Echogr 2014;24:125-127.

Rathore KS, Hussenbocus S, Stuklis R, Edwards J. Novel strategies for recurrent cardiac myxoma. Ann Thorac Surg 2008;85:2125-2126. 
Salcedo EE, Cohen GI, Write RD, Davison M. Cardiac tumors. diagnosis and management. Curr Probl Cardiol 1992;17:73-137.

Sheu CC, Lin SF, Chiu CC, et al. Left atrial sarcoma mimicking obstructive pulmonary disease. J Clin Oncol 2007;25:1277-1279.

Strecker T, Agaimy A. Giant left atrial myxoma causing drop attacks by prolapsing into the mitral valve. Int J Clin Exp Pathol 2012;5:996-999.

Suraj M, Pressman GS, Figueredo WM. Primary cardiac tumors. Int J Cardiol 2009;133:152-156.

Wintersperger BJ, Becker CR, Gulbins H, et al. Tumors of the cardiac valves: imaging findings in magnetic resonance imaging, electron beam computed tomography, and echocardiography. Eur Radiol
2000;10:443-449.

Yamada T, Hirose H, Umeda S, Murakawa S, Mori Y, Iwata H. Right ventricular myxoma - case report and review of the literature. Nippon Kyobu Geka Gakkai Zasshi 1993;41:1069-1107.

Ying L, Lin R, Gao Z, Qi J, Zhang Z, Gu W. Primary cardiac tumors in children: a center's experience. J Cardiothorac Surg 2016;11:52.

Yuan SM. Cerebral infarction due to cardiogenic emboli originating from atrial myxoma: a case report. Changhua J Med 2014;12:87-92.

Yuan SM, Wang SG. Cardiac myxoma presenting as vertigo and paresthesia of the extremities. Acta Med Mediterr 2014;29:105-109. 